RBEn, $30: 262-273,1977$

\title{
MANUAL de SERVIÇo PARA CENTRO de TREINAMENTO*
}

\author{
Maria Grasiela Teixeira Barroso ** \\ Eneida Schramm Frazão***
}

$\operatorname{RBEn} / 05$

BARROSO, M.G.T. e FRAZAO E.S. - Manual de serviço para centro de treinamento. Rev. Bras. Enf.; DF, $30:$ 262-273, 1977.

\section{INTRODUÇAO}

O desenvolvimento organizacional faz com que qualquer departamento ou setor de uma Instituição prepare, imprima e distribua Manuais de Serviço aos seus servidores.

O Manual que aqui apresentamos contém instruções simples, claras, autênticas e atualizadas. $\mathrm{E}$ o resultado de uma profunda observação em nossa experiência de trabalho, quer como chefe de Centro de Treinamento, quer como instrutor, ministrando cursos em repartiçōes públicas; nessas atividades, sentimos a necessidade de organizar, dentro das mais modernas técnicas de administração, aquilo que se faz regularmente.

Um manual semelhante foi escrito, originariamente para cumprir uma das etapas de um curso de Administração de Treinamento, para treinadores, mas a mensagem que encerra o seu conteúdo dirige-se aos supervisores, aos chefes de serviços e aos administradores. Nas mãos destes profissionais repousa o ponto chave do desenvolvimento organizacional.

Após auscultarmos opiniōes, testar essa ou aquela rotina de trabalho, podemos chegar à elaboração deste Manual, que julgamos de grande $u^{t}$ ilidade, desde que nele estāo traçados as Normas Gerais e Instruçōes para Treinamento te Pessoal, aplicáveis a qualquer setor de atividade.

Seu propósito é reunir competências, atribuiçōes e rotinas suscetiveis de utilização por parte daqueles que fazem treinamento, e sem as quais o órgão de treinamento não poderia alcançar os seus objetivos.

* Tema Livre apresentado no XXVII CBen - RJ.

* Auxiliar de Ensino do Curso de Enfermagem do Centro de Ciências da Saúde da Universidade Federal do Ceará; Ex-Chefe do Centro de Treinamento da Secretaria de Saúde do Ceará.

*** Professor Monitor do Departamento de Organizaçāo e Projetos Administrativos; Professora da Escola de Enfermagem Sāo Vicente de Paulo, da Fundação Educacional do Ceará - FUNEDUCE. 
BARROSO, M.G.T. e FRAZAO E.S. - Manual de serviço para centro de treinamento. Rev. Bras. Enf.; DF, 30 : 262-273, 1977.

A vista dessas afirmações, são objetivos específicos deste trabalho:

a. condensar, em um Manual, subsídios úteis a todos aqueles que fazem treinamento;

b. oferecer um modelo de Manual de Serviço aos chefes, supervisores e administradores.

Esperamos, assim, que o presente Manual sirva de instrumento de consulta e possa ser adaptado a outros setores de atividade pública ou privada. Partindo deste Manual, outros serão elaborados e mantidos atualizados, pois o que era eficiente ontem, necessariamente não o é hoje e nem será amanhã.

2. FINALIDADE E ESTRUTURA ORGANIZACIONAL DO CENTRO DE TREINAMENTO

O Centro de Treinamento (C.T.), órgão indispensável a toda Instituição pública ou privada, tem por finalidade o desempenho de tarefas ligadas a treinamento, cabendo-lhe especificamente:

a. promover o levantamento das necessidades de treinamento do pessoal em exercício e/ou para ingresso na Instituição;

b. programar e promover a execução de todas as modalidades de treinamento de pessoal, de conformidade com as normas da Instituição.

Dentro da estrutura organizacional da Instituição, o Centro de Treinamento está subordinado ao Departamento competente e se compõe da Unidade de Cursos, em nível de seção, com os setores a ela subordinados: Curso de Capacitação, Aperfeiçoamento e Atualização, e o de Acompanhamento e Avaliação; a Seção de Atividades Administrativas, com os setores de Expedicnte e de Comunicaçōes; a Seção de Recursos Polisensoriais, com os setores de Desenho e de Projeção e Fotografia.

\section{COMPETENCIA DA UNIDADE DE} CURSOS E DAS DEMAIS SEÇOES

A Unidade de Cursos, órgão executor e coordenador de todas as modalidades de treinamento, funciona por meio dos seus diversos setores (já descritos em 2.). Ao Setor de Cursos de Capacitação, Aperfeiçoamento e Atualização cabe fazer o levantamento das necessidades, o planejamento e a execução de programas e o preparo do material didático pertinente, entre outras tarefas.

O Setor de Acompanhamento e Avaliação tem como competência o controle e a avaliação dos trabalhos e do aproveitamento dos participantes.

A Seção de Atividades Administrativas, órgão auxiliar especificamente incumbido das atividades-meio, funciona através dos seus setores ( $j a ́$ descritos em 2.). Ao Setor de Expediente compete o controle da freqüência dos servidores do C. T., a execução dos serviços datilográficos e de impressão mimeográfica, além da manutenção, ordem e limpeza das dependências, móveis, equipamentos e materiais utilizados pelo C. T.

Ao Setor de Comunicações cabe controlar a correspondência e publícaçōes recebidas e expedidas, manter fichários e arquivos organizados e atualizados.

A Seção de Recursos Polisensoriais, órgão auxiliar especificamente responsável pela execução, guarda e conservação do equipamento e material didático para os treinamentos, funciona por meio dos seus setores (já descritos em 2.). Ao Setor de Desenho compete executar desenhos diversos e confeccionar gráficos, álbuns seriados e cartazes.

O Setor de Projeção e Fotografias zela pelo bom funcionamento das máquinas de projeção e gravação e executa serviços com essís máquinas. (Ver Anexo 2). 
BARRoso, M.G.T. e FRAzAo E.S. - Manual de serviço para centro de treinamento.

Rev. Bras. Enf.; DF, $30: 262-273,1977$.

4. ATRIBUIÇOEES DOS CHEFES E DOS DEMAIS ELEMENTOS DO C. T.

As atribuições pertinentes ao Chefe do C. T., aos Chefes de Seção e às demais funçōes estão descritas em Anexo 3.

\section{ROTINAS}

Sempre que o trabalho do servidor for realizado numa tramitação diária ou periódica, torna-se necessário ao bom funcionamento das atividades uma sistematização das rotinas, observando uma seqüência lógica e racional. (Ver Anexo 4).

\section{CONCLUSOEES E RECOMENDAÇOES}

Acreditamos que o Manual de Serviço é um excelente instrumento de administração. Define competências, atribuiçōes, normas e rotinas, fatores estes indispensáveis 20 desenvolvimento organizacional.

Entretanto, sem a participação do Chefe do Serviço na elaboração do Manual, pouco ou nada será obtido.

Recomendamos aos diretores, chefes e subordinados que utilizem o Manual de Serviço como peça indispensável à administração e organização do trabalho.

\section{RESUMO}

O presente Manual de Serviço, contendo instruçōes simples, claras, autênticas e atualizadas, é o resultado de observação da experiência de trabalho de uma das autoras, como administradora, e de ambas como instrutoras de Centro de Treinamento para servidores da administração pública e privada, no Estado do Ceará.

A finalidade do Centro é o desempenho de tarefas ligadas ao treinamento, cabendo-lhe, especificamente, promover o levantamento das necessidades de treinamento do pessoal em exercício ou dos ingressantes na Instituição, bem como programar e promover a execução de todas as modalidades de treinamento de pessoal.

Preocuparam-se, as autoras, em descrever a competência das diversas seçōes e setores que compõem o Centro, assim como em definir as atribuiçōes das diferentes chefias e demais funçōes, lembrando que há sempre uma função específica para o servidor do Centro, correspondente ao desempenho de determinadas tarefas.

Lembraram, ainda, a necessidade de uma sistematização atualizada das rotinas, com uma seqüência lógica e racional, sempre que o trabalho do servidor for realizado numa tramitação diária ou periódica. Visando atender a esta necessidade, incluíram algumas rotınas mais usadas no Centro de Treinamento, tais como: Coordenação de Curso, Ministração de Curso, Secretaria de Curso e uso da Biblioteca.

Como conclusão, as autoras citam o Manual de Serviço como peça indispensável à administração e organização do trabalho.

\section{REFERENCIAS BIBLIOGRAFICAS}

HARR, Miller - Organização e Métodos. Río de Janeiro, Fundação Getúlío Vargas, 1975.

LERNER, Walter - Organização, Sistemas e Métodos. São Paulo, Atlas, 1975.

LIMA, Oceanira Andrade e PERDIGAO, Lenira S. - Meanual de Enfermagem da
Secretaria de Saúde. Fortaleza, Ceará. 1971.

MIRANDA, G. J. Mac-Dowell dos Passos Organização e Métodos. São Paulo, Atlas, 1976.

WILLIAM, H. Newman - Ação Adminstratíva. 4." ed., São Paulo, Atlas, 1975. 


\section{COMPETENCIAS}

\section{COMPETENCIA DA UNIDADE DE CURSO E DEMAIS SEÇŌES}

\section{UNIDADE DE CURSOS}

\subsection{Pelo setor de Cursos de Capacitação, Aperfeiçoamento e Atualiaação:}

a. colaborar no planejamento das atividades do C.T.;

b. realizar levantamento das necessidades de treinamento;

c. elaborar projetos e planos de treinamento;

d. controlar a execução e andamento dos diversos cursos realizados no C.T.;

- participar da seleção e do recrutamento de candidatos; .... ........

f. preparar cronograma dos treinamentos;

g. identificar o candidato através de prenchimento do formulário de inscrição;

h. desenvolver atividades de relaçōes públicas no que se refere ao andamento dos cursos, após comunicação à Chefia;

i. elaborar estatisticas trimestrais dos treinamentos realizados;

j. participar de programas especiais de treinamento de outras instituiçōes, sempre que houver autorização da Chefia;

1. ministrar cursos através dos instrutores do C.T., ou de professores de outras instituiçōes;

m. preparar manuais, apostilas e outro material didático necessário à realização dos cursos;

n. providenciar a expedição de certificados.

\subsection{Pelo Setor de Acompanhamento e Avaliação:}

a. manter controle diário sobre o andamento dos cursos que estiverem sendo ministrados no C.T.;

b. acompanhar o registro de atividades programadas pelos instrutores;

c. avaliar o trabalho executivo no seu aspecto didático, com o fím de zelar pela manutenção do elevado padrão técnico dos cursos;

d. acompanhar e avaliar o aproveitamento dos participantes dos cursos;

e. controlar o registro de freqüência dos participantes;

f. proporcionar aos participantes apoio técnico e moral;

g. cadastrar instrutores que ministram aulas no C.T.;

h. manter atualizado o registro de dados sobre a avaliação parcial e global de eada treinamento realizado;

1. organizar e manter atualizado um fichário para cadastramento do pessoal treinado pelo C.T. 
BARROSO, M.G.T. e FRAZAO E.S. - Manual de serviço para centro de treinamento. Rev. Bras. Enf.; DF, $30: 262-273,1977$.

\section{SESSAO DE ATIVIDADES ADMINISTRATIVAS}

\subsection{Pelo Setor de Expediente:}

a. controlar a freqüência dos servidores do C.T.;

b. executar serviços datilográficos em geral;

¿. executar serviços de impressão mimeográfica, mantendo em ordem o acervo de estêncil;

d. fazer revisão de estêncil e de trabalhos datilográficos;

e. manter organizados os fichários do setor;

f. requisitar e guardar o material de consumo do C.T.;

๖. Droceder à distribuição do material, mediante requisição;

n. zelar pela conservação e segurança do material em estoque no setor;

1. zelar pela conservação de máquinas, móveis e utensílios em uso no C.T., providenciando as consertos e reparos que se fizerem necessários;

j. zelar pela manutenção e limpeza das dependências, móveis, máquinas e utensílios do C.T.

\subsection{Pelo Setor de Comunicações:}

a. receber, classificar, registrar e controlar a correspondência e publicaçōes recebidas e expedidas no C.T.;

b. organizar e manter sob sua guarda o arquivo de correspondência;

c. redigir toda a correspondência do C.T.;

d. manter fichário organizado e atualizado com indicações sobre meios de comunicação de interesse para os serviços do C.T.;

e. organizar e manter atualizado o fichário nominal com os endereços das autoridades e instituiçōes que mantenham relaçōes com o órgão;

f. lavrar certidōes cujo fornecimento tenha sido autorizado pela Chefia;

g. manter organizado e atualizado o arquivo morto do C.T.

\section{SEÇAO DE RECURSOS POLISENSORIAIS}

\subsection{Pelo Setor de Desenho:}

a. execular desenhos diversos para simbolização visual;

b. confeccionar gráficos diversos;

c. confeccionar álbuns seriados e cartazes diversos;

d. executar desenhos em estêncil;

e. preparar transparências;

f. colaborar na execução de trabalhos mimeográficos.

\subsection{Pelo Setor de Projeção e Fotografias:}

a. zelar pelo bom funcionamento das máquinas de projeção e gravação;

D. executar serviços com máquinas de projeção e gravação;

c. organizar e manter atualizados os arquivos de slides e transparências;

d. controlar e manter em ordem o serviço de fotografias do C.T. 
BARROSO, M.G.T. e FRAZAO E.S. - Manual de serviço para centro de treinamento. Rev. Bras. Enf.; DF, 30 : 262-273, 1977.

\section{ATRIBUIÇōeS DAS CHEFIAS E DAS DEMAIS FUNÇőES}

\section{CHEFE DO CENTRO DE TREINAMENTO:}

a. dirigir, orientar, coordenar e controlar os trabalhos do C.T.;

b. participar na elaboraçāo do plano anual de trabalho e do cronograma de atividades da Instituição;

c. assessorar tecnicamente os coordenadores e instrutores na elaboração dos programas e manuais de cursos;

d. promover com a periodicidade desejável, reuniōes com a Administração Superior, com o fim de analisar necessidades de treinamento e programar atividades correlatas;

e. despachar pessoalmente com o Diretor do Departamento;

f. atender as partes interessadas em treinamento;

g. Indicar os servidores que devam exercer as chefias das seçōes;

h. submeter anualmente ao Diretor do Departamento o Plano de Trabalho do C.T.;

1. manter contato permanente com os supervisores do Departamento, para planejamento dos cursos, treinamentos e estágios;

j. reunir, semanalmente, os chefes e instrutores para discutir e assentar providências;

1. aoresentar relatório trimestral das atividades do serviço ao Diretor do Departamento;

m. elaborar e manter atualizado o Manual de Treinamento da Instituição;

n. participar de investigaçōes e pesquisas puras e aplicadas que objetivem a manutenção e o aperfeiçoamento das atividades do C.T.;

o. propor ao Diretor do Departamento as providências que julgar convenientes ao aperfeiçoamento do serviço;

p. executar e fazer executar as normas do Manuel de Serviço e atualizá-las, sempre que se fizer necessário;

q. responsabilizar-se pelo material permanente do C.T.;

r. exercer outras atribuiçōes que lhe forem conferidas em lei ou regulamento.

\section{CHEFES DE SEÇAO:}

a. orientar e supervisionar a execução dos trabalhos das seçōes;

b. despachar pessoalmente com o chefe do C.T.;

c. apresentar mensalmente ao Chefe do Serviço resumo das atividades da seção e, anualmente, relatório dos trabalhos realizados, em andamento e planejado; 
BARROSO, M.G.T. e FRAZAO E.S. - Manual de serviço para centro de treinamento. Rev. Bras. Enf.; DF, $30: 262-273,1977$.

d. propor a o Chefe do Serviço medidas convenientes à boa execução dos trabalhos;

e. zelar pela disciplina dos recintos de trabalho, fazendo cumprir as normas estabelecidas no Manual de Serviço e cuidando de sua atualização;

f. opinar sobre os assuntos relativos às atividades da seção;

g. dar informaçōes e pareceres, submetendo-os à apreciação do Chefe do Serviço;

h. zelar pela guarda e conservação de todo o material permanente e de consumo existente na seção;

1. reunir, mensalmente, os servidores da seção para discutír e apresentar providências;

j. exercer outras atribuiçōes que the forem conferidas.

\section{INSTRUTOR DO C.T.;}

a. recrutar e selecionar pessoal, de acordo com os subsídios dados pelos supervisores da Instituição;

b. participar da elaboração e execução de projetos e programas para capacitação e aperfeiçoamento de pessoal da Instituição, de acordo com as necessidades dos treinamentos respectivos;

c. colaborar no planejamento das atividades do C.T.;

d. participar das reuniōes administrativas e técnicas convocadas pela Chefia;

e. substituir o Chefe da Unidade de Cursos, nas suas ausências ou impedimentos eventuais, quando para isso for designado;

f. assumir, eventualmente, a coordenação de curso, por indicação da Chefia;

g. participar de programas especiais de treinamento de outras instituiçōes, sempre que for designado pela Chefia;

h. manter contato permanente com a Chefia da Unidade de Cursos, informando-a sobre o andamento do curso que estiver ministrando, de modo a possibilitar uma eficiente supervisão;

1. avaliar o trabalho executivo na sua esfera, junto ao Setor de Acompanhamento e Avaliação;

j. apresentar relatório trimestral das suas atividades à Chefia;

1. planejar e ministrar cursos;

m. manter contato com o Coordenador de Cursos, informando-o sobre o aproveitamento dos participantes;

n. preparar manuais, apostilas e outro material didático do curso que estiver ministrando;

o. colaborar com o Coordenador do Curso na avaliação global dos participantes.

\section{COORDENADOR DO CURSO:}

a. Realizar levantamento das necessidades de treinamento;

b. Participar da seleção e do recrutamento de candidatos para treinamento;

c. Colaborar com a Unidade de Cursos, na elaboração do Projeto e Plano de Curso;

d. Estabelecer contato prévio com os Instrutores, definindo responsabilidades e interpretando para os mesmos a filosofia e os objetivos do curso; 
BARROSO, M.G.T. e FRAZAO E.S. - Manual de serviço para centro de treinamento.

Rev. Bras. Enf.; DF, 30 : 262-273, 1977.

e. Manter contato permanente com a Chefia da Unidade de Cursos e o Secretário, sobre o andamento do curso;

f. Supervisionar e avaliar o aproveitamento dos participantes do curso, mantendo registro atualizado das atividades dos mesmos;

g. Avaliar o trabalho executivo no seu aspecto didático, com o fím de zelar pela manutençāo do elevado padrāo técnico do curso;

h. Substituir o Instrutor nos seus impedimentos eventuais;

1. Proporcionar aos participantes dos cursos apoio técnico e moral;

j. Apresentar relatório à Chefía da Unidade de Cursos sobre a avaliação global do treinamento realizado;

1. Executar outras tarefas correlatas.

\section{SECRETARIO DE CURSO:}

a. Fazer e manter atualizada a relaçāo dos participantes do Curso, a qual deve ser assinada pelo Chefe do Centro de Treinamento e pelo Coordenador do Curso;

b. Receber dois (2) retratos $3 \times 4$ de cada participante do Curso, para a ficha individual;

c. Preencher as fichas dos participantes de acordo com o modelo;

d. Manter organizado o material necessário ao serviço da Secretaria;

e. Datilografar e mimeografar todo o material necessário ao desenvolvimento do Curso;

f. Prestar informaçōes aos participantes dentro das suas atribuiçōes;

g. Manter endereço completo dos colaboradores do Curso;

h. Preparar folha de freqüência dos participantes;

1. Fazer previsāo do material necessário ao Curso e encaminhar relação do mesmo ao Coordenador para as devidas providências;

j. Prever diariamento o material que será necessário para ministraçāo das aulas;

1. Manter o local de trabalho devidamente organizado;

m. Executar outras tarefas correlatas.

\section{RESPONSAVEL PELA BIBLIOTECA:}

a. Fazer o registro de livros e periódicos adquiridos por compra, doaçāo, etc.;

b. Numerar e catalogar os livros;

c. Preparar etiquetas para empréstimos de livros;

d. Organizar pastas para transparências, com discriminação dos respectivos assuntos;

e. Organizar pastas com apostilas de cursos para estudo ou pesquisa;

f. Organizar pastas contendo leis, regulamentos e regimentos do C. T.;

g. Organizar pastas para guarda de material visual;

h. Organizar pastas contendo programas e projetos de cursos realizados;

i. Controlar entradas e devoluçōes de transparências usadas para os treinamentos;

j. Organizar fichário para guarda e controle das etiquetas para empréstimos de livros; 
BARROSO, M.G.T. e FRAzAo E.S. - Manual de serviço para centro de treinamento. Rev. Bras. Enf.; DF, 30 : 262-273, 1977.

1. Elaborar normas para o uso da biblioteca e mantê-las atualizadas;

m. Apresentar ao coordenador do curso, controle estatístico do material didático utilizado em cada treinamento;

n. Executar outras tarefas correlatas.

\section{OFICIAL DE ADMINISTRAÇAO:}

a. Orientar e revisar trabalhos referentes a assuntos de caráter geral ou específico do H.C.T.

b. Estudar processos referentes a assuntos de caráter geral ou específico que apresentem complexidade, preparando os expedientes que se fizerem necessários, tais como: Ofícios, Relatórios, Exposiçōes de motivos, Pareceres e Informaçōes;

c. Colaborar na elaboração do orçamento-programa do C. T.;

d. Participar dos trabalhos de levantamento de dados;

e. Apresentar dados para confecção de relatórios técnicos do C. T.;

f. Fornecer dados estatísticos referentes aos treinamentos;

g. Executar outras tarefas correlatas.

\section{ESCRITURARIO:}

a. Receber, conferir, classificar, fichar e preparar expedientes do C. T., providenciando a sua distribuição e expedição;

b. Organizar o documentário do C. T. efetuando serviços de cadastro, fichárín e arquivo, mantendo-os atualizados de acordo com determinação superior;

c. Controlar a movimentação de processo ou papéis no C.T., entre seçōes e/ou servidores;

d. Conferir, informar e anotar expedientes simples ou que exijam algum discernimento e capacidade crítica e analítica;

e. Coletar dados junto aos órgãos públicos e privados de interesse do C. T.;

f. Preparar fichas e folhas de pagamento, efetuando os cálculos que se fizerem necessários;

g. Fornecer, quando solicitado, dados estatísticos referentes aos treinamentos;

h. Executar outras tarefas correlatas.

\section{DATILOGRAFO:}

a. Executar trabalhos datilográficos em geral;

b. Conferir o trabalho após datilografá-lo;

c. Arquivar as segundas vias dos documentos;

d. Executar outras tarefas correlatas.

\section{ENCARREGADO DOS RECURSOS POLISENSORIAIS:}

a. Preparar transparências;

b. Executar desenhos em estênsil e outros;

c. Confeccionar gráficos e cartazes diversos; 
BARROSO, M.G.T. e FRAZĀO E.S. - Manual de serviço para centro de treinamento. Rev. Bras. Enf.; DF, 30 : 262-273, 1977.

d. Colaborar na execução de trabalhos mimeográficos;

e. Zelar pelo bom funcionamento das máquinas de projeção e gravação;

f. Organizar e manter atualizado o arquivo de slides e transparências;

g. Extrair cópias ou reproduçōes de documentos na máquina copiadora;

h. Manter em ordem as fotografias do C. T.;

i. Executar outras tarefas correlatas.

\section{MOTORISTA :}

a. Receber ordens do Chefe do C. T. ou do seu substituto eventual, nas suas ausências ou impedimentos;

b. Obedecer as instruçōes específicas para o desempenho de suas atribuições diárias;

c. Comunicar, imediatamente, à Chefia do C.T., qualquer acidente e outros problemas que exijam providências urgentes;

d. Zelar pela conservação, limpeza e manutenção do veículo;

e. Verificar, antes de iniciar qualquer viagem ou jornada de trabalho, as condiçōes de segurança do veículo;

f. Providenciar junto à Chefia sobre revisōes, conserto, lavagens e lubrificaçōes do veículo;

g. Responsabilizar-se pelos danos que causar ao veículo por imperícla, imprudência ou negligência no exercício da função;

h. Fornecer, diariamente, ocorrências especiais e a quilometragem ao responsável pelo controle do veículo;

1. Apresentar-se a o Serviço sempre devidamente uniformizado;

j. Observar o horário indicado pela Chefia do C. T.;

1. Recolher o veículo ao C. T.; no final do expediente;

m. Executar outras tarefas correlatas.

12. SERVENTE:

a. Limpar as dependências do C. T. diariamente;

b. Limpar os móveis, diariamente.

c. Trocar as toalhas dos lavatórios, quando necessário;

d. Preparar e servir o café nos horários estabelecidos;

e. Abrir e fechar as portas do C. T. nos horários estabelecidos;

f. Encerar o piso das dependências do C. T.;

g. Limpar portas e janelas, semanalmente;

h. Remover lixos e detritos;

1. Ajudar a remover, transportar ou arrumar móveis, equipamentos e material;

j. Distribuir correspondência interna e externa;

1. Executar outras tarefas correlatas. 
BARROSO, M.G.T. e FRAZAO E.S. - Manual de serviço para centro de treinamento.

Rev. Bras. Enf.; DF, $30: 262-273,1977$.

\title{
ROTINAS:
}

\author{
COORDENAÇAO DE CURSOS \\ DESCRIÇAO DOS PASSOS
}

Recebe e examina comunicação do chefe do C. T. sobre coordenação de curso;

Colabora na seleção e no recrutamento de candidatos para treinamento;

Participa com o chefe da Unidade de Cursos na elaboração de projetos e planos de cursos;

Estabelece contato prévio com os Instrutores de Ensino, definindo a programação de curso;

Mantém contato permanente com a chefia da Unidade de Curso e o Secretário indicado, sobre o ínício e o andamento do curso;

Mantém sob controle a execução do curso através de registro atualizado das atividades;

Substitui o Instrutor nos seus impedimentos eventuais;

Supervisiona e avalia aproveitamento dos participantes;

Proporciona aos participantes do curso apoio técnico, moral e social;

Avalia o trabalho executivo dos instrutores. no seu aspecto didático;;

Elabora e encaminha relatórios à chefia da Unidade de Cursos sobre Treinamento realizado;

Executa outras tarefas correlatas;

Faz os devidos registros;

Arquiva e/ou guarda material do curso.

\section{MINISTRAÇAOO DE CURSO \\ DESCRIÇAO DOS PASSOS}

Recebe e examina comunicação da chefia do C. T., através do chefe da Unidade de Cursos, sobre a data do início de curso;

Recruta e seleciona pessoal para os cursos;

Participa da elaboração e execução de projetos e programas de capacitação e aperfeiçoamento de pessoal;

Planeja e ministra cursos;

Colabora no planejamento das atividades do C. T.;

Participa das reuniōes administrativas e técnicas convocadas pela chefia;

Assume, eventualmente, a coordenação do curso, por indicação da chefia;

Avalia o trabalho executivo na sua esfera, juntamente com as demais membros da equipe do C. T.;

Mantém contato permanente com a Chefia da Unidade de Cursos, informando-a sobre o andamento do curso que estiver ministrando; 
BARROSO, M.G.T. e FRAZAO E.S. - Manual de serviço para centro de treinamento.

Rev. Bras. Enf.; DF, $30: 262-273,1977$.

Participa de programas especiais de treinamento de outras instituiçōes;

Prepara Manuais, apostilas e outro material didático.

Mantém contato com o Coordenador e Chefe da Unidade de Curso, informandoos sobre o aproveitamento dos participantes;

Avalia, individualmente, o curso ministrado;

Colabora com o Coordenador do curso na avaliação global dos participantes;

Entrega ao Chefe da Unidade de Cursos uma via do programa do curso ministrado;

Providencia arquivamento.

\section{SECRETARIA DE CURSO \\ DESCRIÇAO DOS PASSOS}

Presta informação aos interessados;

Preenche as fichas de inscrição dos candidatos mediante documento de identificação;

Entrega ao funcionário 2 retratos $3 \times 4$ para ficha individual;

Faz relação dos participantes, mantendo-a atualizada;

Confere relação com a ficha de inscrição;

Entrega ao candidato o comprovante da inscrição;

Prepara e mantém organizado o material necessário ao serviço da secretaria;

Organiza folha de freqüência dos participantes;

Mantém organizados os endereços dos professores e das diversas instituiçōes colaboradoras do curso;

Faz previsão do material necessário ao curso;

Rncaminha relação do material ao coordenador para as devidas providências;

Prevê e controla diariamente o material a ser utilizado nas aulas;

Mantém o local de trabalho devidamente organizado;

Executa outras tarefas correlatas;

Entrega ao coordenador resumo das atividades do curso;

Arquiva e/ou guarda o material utilizado.

\section{USO DA BIBLIOTECA}

\section{DESCRIÇAO DOS PASSOS}

Registra livros e periódicos adquiridos por compra, doação, etc.;

Numera e cataloga livros;

Confere material catalogado;

Prepara etiqueta e fichas para empréstimo de livros;

Organiza pastas com os diversos assuntos;

Faz registro de material expedido para estatística e controle do aproveitamento dos cursos realizados;

Organiza arquivo e fichário para guarda e controle do material de consulta;

Confere registro de material;

Colabora no manuseio de projetores durante os cursos;

Elabora e atualiza normas par uso da biblioteca;

Controla a entrega e devolução de transparências, livros e periódicos;

Arquiva fichas de controle. 